\title{
Carbohydrate mimics and lectins: a source of new drugs and therapeutic opportunities
}

José J. Reina and Anna Bernardi

Universita' degli Studi di Milano, Dipartimento di Chimica Organica e Industriale, via Venezian 21, 20133, Milano, Italy

\begin{abstract}
Mimics of oligosaccharides capable of interfering with lectin activity are currently being pursued by a number of groups in an effort to produce tools for glycobiology and to design antagonists of medically relevant lectins. The field is reviewed in this chapter. After a brief overview of the state of the art, examples from our and others' studies on the dendritic cell receptor DC-SIGN are illustrated.
\end{abstract}

\section{Introduction}

Glycans are by far the most abundant natural products. Together with nucleic acids, proteins and lipids they constitute the group of biologically essential macromolecules. They are not only an important source of metabolic energy, but are also widely expressed as glycoconjugates on the surface of cells where they play key roles in important biological processes. ${ }^{1-3}$ In the past decade, the increased appreciation for the ubiquity of glycans and their ability to encode biochemical information has generated the field of chemical glycobiology. ${ }^{4}$ Its main objective consists in understanding how chemical information is encoded in sugar structures, how this information is read out by sugar binding proteins (lectins), and how we can control/alter this flow of information by interfering with the sugar code. A major contribution to the understanding of the sugar code is expected to emerge from screening of glycan arrays ${ }^{5}$ and from the use of chemoinformatic tools. Glycan-specific databases have been built ${ }^{6}$ and data mining has begun. $^{7}$ Glycomimetic molecules that can disrupt the formation of sugar-protein complexes may be used in this context as probes of biological processes and may provide ideas for medicinal applications. ${ }^{8}$

So far, most of this work has been directed towards enzymes that tailor glycan determinants: glycosidases and glycosyltransferases. Inhibition of glycosidases has been particularly fruitful: azasugars of the nojirimycin family are well-established, generalpurpose inhibitors. ${ }^{9}$ Sialidase inhibitors have been developed in one of the first successful rational drug-design projects, ${ }^{10}$ and are currently commercialized as anti-flu drugs under the commercial names of Relenza (Zanamivir) and Tamiflu (Oseltamivir). Inhibition of glycosyltransferases, until very recently, has proven harder, mainly due to the lack of robust non-radiometric assay strategies to detect glycosylation, but important steps forwards are being made. ${ }^{11}$

Less is known about the inhibition of lectin-mediated sugar recognition. As opposed to sugar-processing enzymes, lectins are proteins that recognize glycans with high specificity, but lack enzymatic activity on their ligands. Lectins are implicated in cellcell self-recognition processes, cell-extracellular matrix interaction, gamete fertilization, embryonic development, cell growth, cell differentiation, cell signalling, cell adhesion and migration, apoptosis, immunomodulation and inflammation, host-pathogen interactions, glycoprotein folding and routing, mitogenic induction and homeostasis. ${ }^{12}$ Thus, in principle, lectins can clearly be considered as potential targets for the development of new drugs. ${ }^{8 \mathrm{a}, 13,14}$ However, they have rarely been exploited for the discovery of novel therapeutic opportunities. In the past, medicinal chemists have 
mostly disregarded carbohydrates as a class of molecules for drug development. The high density of functional groups and the immense variety of complex structures of glycans ${ }^{15}$ represent a great challenge for the development of antagonists. Furthermore, carbohydrates themselves are too hydrophilic to have good bioavailability. Only in some cases where oral availability is not required, such as the inhibition of $\alpha$ glycosidases for the treatment of diabetes by voglibose, ${ }^{15}$ the inhibition of viral neuraminidases for the treatment of influenza ${ }^{10}$ or the inhibition of viral adhesion to epithelia, ${ }^{16}$ carbohydrate-related compounds have been used by medicinal chemists as target for the design of new bioactives molecules. Additionally, the recognition of sugars by lectin is intrinsically a low-affinity process. Typically, lectins possess shallow binding sites, exposed on their surface and endowed with low affinity for individual, monovalent oligosaccharides. Nonetheless, they can display exquisite target specificity for certain cellular glycans. For example, Galectin-1 specifically recognises a galactose residue but not a glucose residue. ${ }^{2 a, 17}$

A further limitation for the application of carbohydrates as drugs is the lability of glycosidic bonds to hydrolytic enzymes (glycosidases) in vivo. This can be circumvented by developing new glycomimetic compounds able to mimic the biological activity of native glycans and to solve the negative features that limit the biological application of carbohydrates. Progresses in the development of glycomimetics targeted against sugar binding proteins (lectins) have been reviewed recently. ${ }^{8,13,14}$ Additional recent examples include glycomimetic antagonists of selectins, ${ }^{18}$ of cholera toxin $\mathrm{B},{ }^{19}$ of E. coli FimH binding to epithelial cells, ${ }^{20} \mathrm{MAG}$ antagonists and other Siglec binding agents, ${ }^{21} \mathrm{C}$-glycoside ligands of Pseudomonas aeruginosa PA-IL lectin. ${ }^{22}$ In the present review, after describing some general characteristics of glycomimetic structures and of their design and to recapitulate some points about medically relevant lectins, we will describe some examples of design synthesis and characterization of monovalent and multivalent antagonists of the dendritic cell C-lectin DC-SIGN (dendritic cell-specific intercellular adhesion molecule 3 -grabbing non integrin), ${ }^{23}$ implicated in many infection processes.

\section{Glycomimetic structures}

Many modifications have been introduced in the structure of carbohydrates to upgrade the drug-like characteristics of this class of biomolecules and to generate glycomimetics. The main modifications have been directed to increase the stability of carbohydrates to enzymatic degradation. The endocyclic oxygen can be replaced by a carbon atom (cyclitols or carbasugars), a nitrogen atom (iminosugars), a sulfur atom (thiosugars) or a phosphorus atom (phosphasugars). ${ }^{9 c, 24}$ Alternatively, the exocyclic oxygen can be substituted by the same set of atoms, giving, respectively, C-glycosides, $\mathrm{N}$-glycosides, thioglycosides and P-glycosides. A recent review by Werz et al. describes the latest advances in the synthesis of this kind of carbohydrate mimetics. ${ }^{25}$ Elimination or substitution of hydroxyl groups by other functional groups, introduction of aliphatic or aromatic substituent in the structure of the glycomimetic or use different ring sizes are others possibilities to mimic carbohydrates. In some cases, glycomimetics are generated by the introduction of pharmacophoric groups on the sugar backbone or by modifications of glycoconjugates where the carbohydrate part itself is altered, for example in the case of truncated glycans missing a monosaccharide or a larger part of the native structure. Replacement of oligosaccharide fragments with conformationally designed scaffold elements has also been exploited. ${ }^{8 \mathrm{~b}}$ 
Since Nature uses multivalency to improve the affinity and specificity in carbohydratereceptor interaction, glycomimetic structures directed towards lectins are often built to suit a multivalent inhibition approach. ${ }^{26}$

\section{Rational design of unnatural inhibitors of lectins}

The identification of unnatural inhibitors of lectin-sugar recognition has been approached mostly through rational design and synthesis of glycomimetic structures, although, more recently, non-carbohydrate lectin binders have also been described. ${ }^{27}$ In this context, glycomimetics are non-carbohydrates that attempt to reproduce the 3D structure of oligosaccharides' binding determinants and thus to compete with the natural ligand for a target lectin. They are often composed of a mono- or disaccharide, working as the lectin anchor, linked to an aglycone designed to host and orient further functionalities for lectin interaction and to impart to the molecule some pharmacologically favourable properties, such as improved lipophilicity and resistance to hydrolytic enzymes.

The first step in this process is to understand the SAR (Structure Activity Relationship) of the carbohydrate lead, because despite the great structural complexity of many bioactive oligosaccharides, often only small portions of these molecules are actually recognized by their receptors. The remaining part appears to act as a scaffold that orients the binding determinants in the appropriate conformation and provides a connection to the aglycons. The starting point for rational design of glycomimetics is often the analysis of the crystal structure of oligosaccharide-lectin complexes. If X-ray structures are not available, homology models can be generated. ${ }^{28}$ Although oligosaccharides are relatively flexible molecules, if compared to other macromolecules, certain glycans have highly favoured conformations. ${ }^{29}$ In particular, vicinal branching appears to impart a significant conformational restriction, as seen for instance in gangliosides ${ }^{30}$ and in the Lewis determinants. ${ }^{31}$ Different lectins can select different conformations of flexible oligosaccharides. ${ }^{32}$ Some lectins even select conformations that do not appear to be populated by more than $5-10 \%$ in the free state (ground state) of the ligand. This has clearly a consequence on the (low) affinity of such ligands for the target lectin, but it can be exploited by mimics that, by chance or design, happen to stabilize the bound conformation.

\section{Lectins}

Lectins are proteins that recognize and bind carbohydrate conjugates, principally glycolipids and glycoproteins. Lectins were initially discovered in plants and in snake venom, but subsequently were also identified in bacteria, viruses, vertebrates, and mammals. and were recognized as the read-out machinery of carbohydrate-encoded information. ${ }^{1}$ The lectin carbohydrate recognition domains (CRD) are often able to recognize complex oligosaccharides in a selective manner; however, the oligosaccharide recognition determinants often consist of only one or two residues, usually located in the non-reducing end of the oligosaccharide structure, that appear to act as anchors driving the entire glycoconjugate to interact with the protein. Several highly conserved types of CRD have been identified in animal lectins. They all share a pattern of invariants and highly conserved aminoacids residues at a characteristic spacing. ${ }^{12 \mathrm{f}}$ Following this criteria most of the animal lectins have been classified into structural 
related families and superfamilies like C-type lectins, P-type lectins, I-type lectins, etc. The most abundant of the animal lectins are the C-type lectins (CTL). The majority of the CTLs are large, asymmetric trans-membrane glycoproteins, with one or more CRDs attached to a variable number of structurally and functionally different polypeptide domains.

The interaction between sugar and lectins is driven by hydrogen bonds, association of monosaccharide residues with metals (for C-type lectins and related calcium-dependent proteins), ionic and hydrophobic interactions, that all contribute to binding affinity. The energy associated with hydrogen bonding in sugar-protein interactions is significantly reduced by competition from bulk solvent and by the flexible nature of hydroxyl groups, which results in a considerable entropic penalty when they become constrained upon binding. Sugar $\mathrm{CH}$ bonds can engage in stacking interactions with protein aromatic side chains, but natural carbohydrates usually lack extended hydrophobic areas, often a dominant factor in high-affinity receptor-ligand interactions. Hence, the affinity of lectins for monovalent carbohydrates is typically weak (dissociation constants are in the $\mathrm{mM}$ to $\mu \mathrm{M}$ range). Most lectins, however, are multimeric and, in general, polyvalent presentations of monosaccharides acting as binding determinants for a given lectin can be used for inhibition, with major affinity increases over the corresponding monovalent ligand. ${ }^{5,33}$ Spectacular results have been achieved through this approach, particularly for $\mathrm{AB}_{5}$ bacterial toxins ${ }^{34},{ }^{19 \mathrm{~b}}$ and more could be achieved through the combination of judicious choice of potent monovalent inhibitors with rationally designed polyvalent scaffolds, a task that will be significantly simplified by the introduction of powerful chemoselective conjugation techniques.

\section{Design and synthesis of DC-SIGN ligands}

DC-SIGN (dendritic cell-specific ICAM-3 grabbing nonintegrin, CD209) was originally defined as an intercellular adhesion molecule-3 (ICAM-3) receptor that play an important role in establishing the first contact between DC-SIGN and resting T cells. ${ }^{23}$ It is a type II trans-membrane C-type lectin with a single C-terminal Carbohydrate Recognition Domain (CRD) within its sequence. In the cellular membrane, DC-SIGN is assembled as a tetramer, thanks to an extended coiled-coil region that allows simultaneous presentation of four CRDs. ${ }^{35}$ DC-SIGN is one of the dendritic cells specific pathogen-uptake receptors and recognizes glycoconjugates on the surface of several pathogens, including viruses (HIV, Ebola, Cytomegalovirus, Dengue, SARS), ${ }^{36}$ bacteria (M. tuberculosis, S. pneumoniae), ${ }^{37}$ fungi (C. albicans, A. fumigatus), ${ }^{38}$ and parasites (Leishmania, S. mansoni). ${ }^{39}$ It has been proven that this lectin plays a key role in the initial steps of infections caused by some of these pathogens. In particular, DCSIGN was brought to attention by the group of van Kooyk, who reported that HIV-1 targets DC-SIGN, but escapes degradation in lytic compartments, thus using DCs (dendritic cells) as a Trojan horse to invade the host organism. ${ }^{36 a}$ Inhibition of DCSIGN is currently considered as an interesting new target for the design of anti-infective agents. ${ }^{40,8}$ The detailed molecular mechanisms by which this receptor operates are not known in detail, thus effective modulators of DC-SIGN are also needed to help clarify the different biological processes in which this receptor is involved. The main carbohydrate ligand recognized by DC-SIGN is the high mannose glycan, $(\mathrm{Man})_{9}(\mathrm{GlcNAc})_{2}$, a branched oligosaccharide presented in multiple copies by several pathogen glycoproteins and specifically by the gp120 envelope protein of HIV. DC- 
SIGN can also recognize branched fucosylated structures bearing terminal galactose residues, such as the Lewis antigens. The primary interaction of oligosaccharides and DC-SIGN occurs by coordination of the a residue of the oligosaccharide (often the nonreducing end one) to a $\mathrm{Ca}^{2+}$ binding site exposed to the surface of the protein. ${ }^{41} \mathrm{X}$-ray data are available for complexes of DC-SIGN carbohydrate recognition domain (CRD) with both mannose oligosaccharides and Lewis-X. ${ }^{41}$

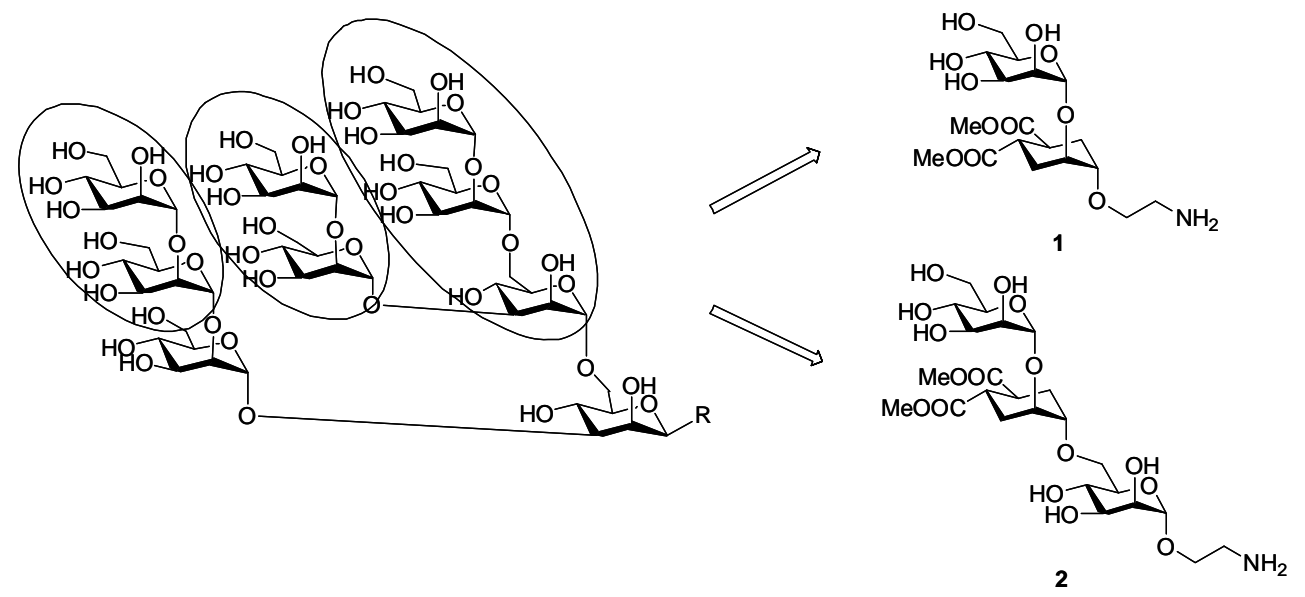

Figure 1. Glycomimetics structures 1 and 2 based on the high-mannose oligosaccharide.

Based on the high-mannose oligosaccharide as a lead structure we have reported ${ }^{42}$ the design and synthesis of glycomimetics compounds that bind to DC-SIGN. It is known that high density arrays of unbranched Man $\alpha(1,2)$ Man bind to DC-SIGN almost as effectively as the entire $\mathrm{Man}_{9}$ oligosaccharide. ${ }^{43}$ To mimic 1,2-mannobioside the pseudo-1,2-mannobioside $\mathbf{1}^{44}$ (Figure 1) was designed, which contains a mannose unit connected to a conformationally locked cyclohexanediol (Figure 1). The latter acts as a mimic of a reducing end mannose residue and features a spacer-arm terminated with azido or amino functionality, useful to generate multivalent DC-SIGN ligands. Design of mimic 1 was supported by modelling and NMR experiments. STD-NMR (saturation transfer difference experiments) showed that the molecule interacts with DC-SIGN and inhibition of Ebola virus entry in DC-SIGN expressing Jurkat cells was also shown. The IC50 measured for 1 in this test $(0.6 \mathrm{~mm})$ was approximately three times lower than that of the natural disaccharide Man $\alpha(1,2)$ Man, which also showed a marked cytotoxicity not exhibited by 1 . The pseudo-trisaccharide, 2, mimicking the linear Man $\alpha(1,2)$ Man $\alpha(1,6)$ Man trisaccharide of the D3 arm of $\mathrm{Man}_{9}$, was designed following the same concept. ${ }^{45}$ This compound inhibits DC-SIGN binding to mannosylated BSA (Bovine serum albumin) with an IC50 of $130 \mu \mathrm{M}$ (by surface-plasmon resonance, SPR). ${ }^{46}$ The affinity for DC-SIGN of both these monovalent ligands is too weak for them to represent effective inhibitors of DC-SIGN-mediated infections and their therapeutic potential is limited. However, appropriate levels of affinity have been obtained when the ligands were presented in a multimeric form. ${ }^{46,47}$ The multimeric presentation of the glycomimetics $\mathbf{1}$ and $\mathbf{2}$ were synthesized by conjugation of the monovalent ligands to tetra- and multivalent scaffolds based on bishydroxymethylpropionic acid as building block. Tetravalent presentation of the pseudotrisaccharide 2 in dendron 3 (Figure 2) was shown to inhibit trans infection of T lymphocytes by DC-SIGN expressing B-cells, which had been pre-incubated with HIV in the presence of 3 . Infection was abrogated almost totally by 3 in $100 \mu \mathrm{M}$ concentration, and an IC50 ca. $10 \mu \mathrm{M}$ could be estimated. 

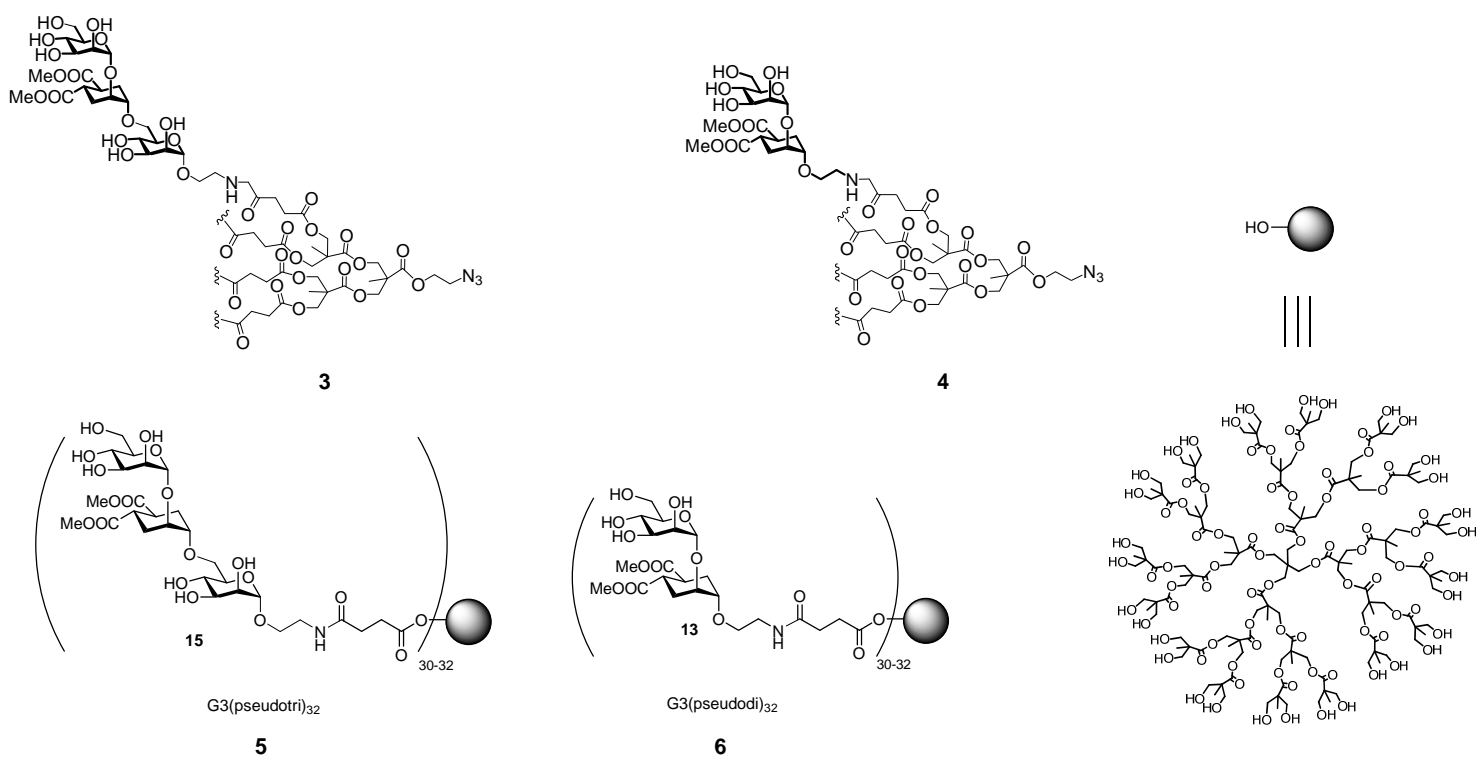

Figure 2. Multivalent presentation of glycomimetics 1 and 2 using dendrons $(3,4)$ and dendrimers $(5,6)$ scaffolds.

Additionally, other multivalent compounds were synthesized to obtain multivalent glycomimetics conjugates with 4-32 copies of the ligands on the surface (3-6, Figure 2) These tetra- and multivalent systems were tested in vitro using an infection model based on pseudotyped viral particles with the Ebola virus envelope glycoprotein GP1. ${ }^{47}$ This infection model is exclusively dependent of DC-SIGN. ${ }^{48}$ In these experiments, the tetravalent systems $\mathbf{3}$ and $\mathbf{4}$ were very active in the low micromolar range, and the multivalent systems $\mathrm{G}_{3}$ (pseudosugar) (p) $_{32}$ showed a very strong inhibition effect with IC50 in the nanomolar range. On the other hand, relatively small differences were observed between equivalent constructs obtained from the two selected monovalent ligands, even if in a monovalent presentation, the pseudotrisaccharide 2 is and order of magnitude more active than the pseudodisaccharide 1. A plausible explanation for these observations could be the loss of differents binding mode of the ligands where they are linked to a scaffold. As a consequence, despite the improved affinity of the pseudomannotrioside at the monovalent level, pseudomannobiose 2 is likely to be an effective lead compound to improve the affinity of these multivalent pseudosaccharide compounds.

A structural modification leading to improve affinity of Man-based ligands was recently reported. ${ }^{49}$ Examination of the crystal structure of DC-SIGN CRD in complex with tetramannoside $\mathrm{Man}_{4}$ (PDB code: $\left.1 \mathrm{SL} 4\right)^{51}$ suggests he presence of a hydrophobic area in the vicinity of the mannose-binding Ca-site of the lectin. Replacing the methyl ester groups on the cyclohexane scaffolds of 1 with secondary amides (Figure 3 ) led to a series of compounds the bis-amides of 1 (Figure 3) that displayed low $\mu \mathrm{M}$ activity in the inhibition of dendritic cells to a mannan coated plate. Further optimization of this lead and characterization of its binding activity and selectivity have recently been completed. ${ }^{50}$ 

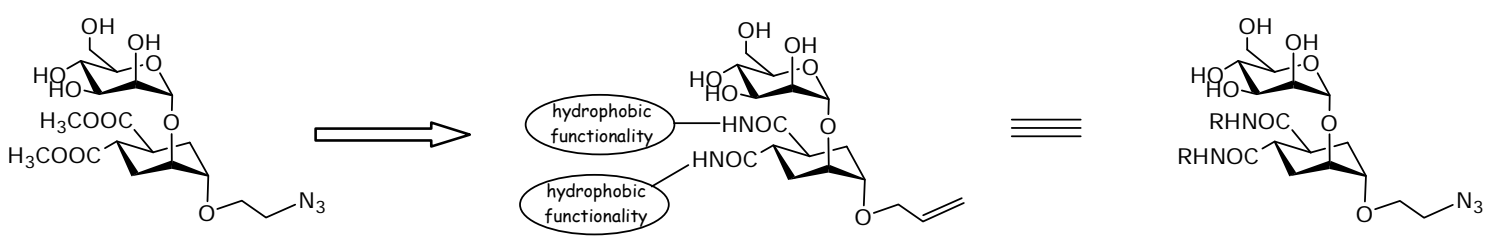

bis-amides of 1
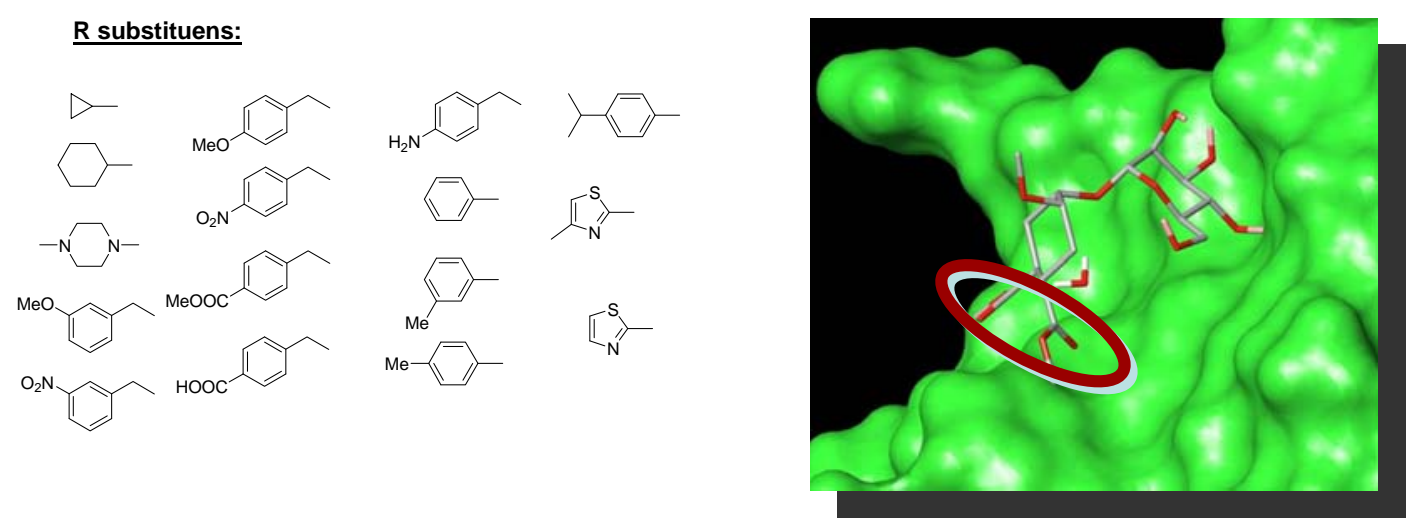

Figure 3. Design of a library of bis-amides based on the structure of glycomimetic 1.

Another approach to prepare man nose mimics working as DC-SIGN inhibitors was described by the group of Kiessling, who used a shikimic acid-derived glycomimetic scaffold of general formula $7 .^{52}$ (Figure 4). The primary interaction of mannose residues with DC-SIGN $\mathrm{Ca}^{2+}$ binding site occurs through the hydroxyl groups at the position 3 and 4 of the sugar. The shikimic acid derivative prepared by Kiessling and co-workers shares the same hydroxyl arrangement as mannose at positions 2, 3 and 4 . In addition to the hydroxyl groups that mimic mannose, the 6-membered ring structure generated from shikimic acid presents two possible points of diversification a carboxy group and a thiol that were exploited to introduce different substituents and to synthesize a library of 192 compounds. They were tested using a fluorescence-based high-throughput competition assay that assessed their ability to compete with immobilized mannan for binding the fluorophore-labeled extracellular domain of DCSIGN. The best compound of the library was 8, which had an $\mathrm{IC}_{50}$ of $11.2 \mathrm{mM}$, but was found to be more selective for DC-SIGN than for mannose-binding protein A (MBP-A). Finally, the multivalent ligand $\mathbf{9}$ was prepared by ring-opening metathesis polymerization (ROMP). ${ }^{53}$ The IC50 value for the polymer 9 was $2.9 \mu \mathrm{M}$, which indicated the polymer is 1000 -fold more potent than the monomeric inhibitor $\mathbf{8}$. 


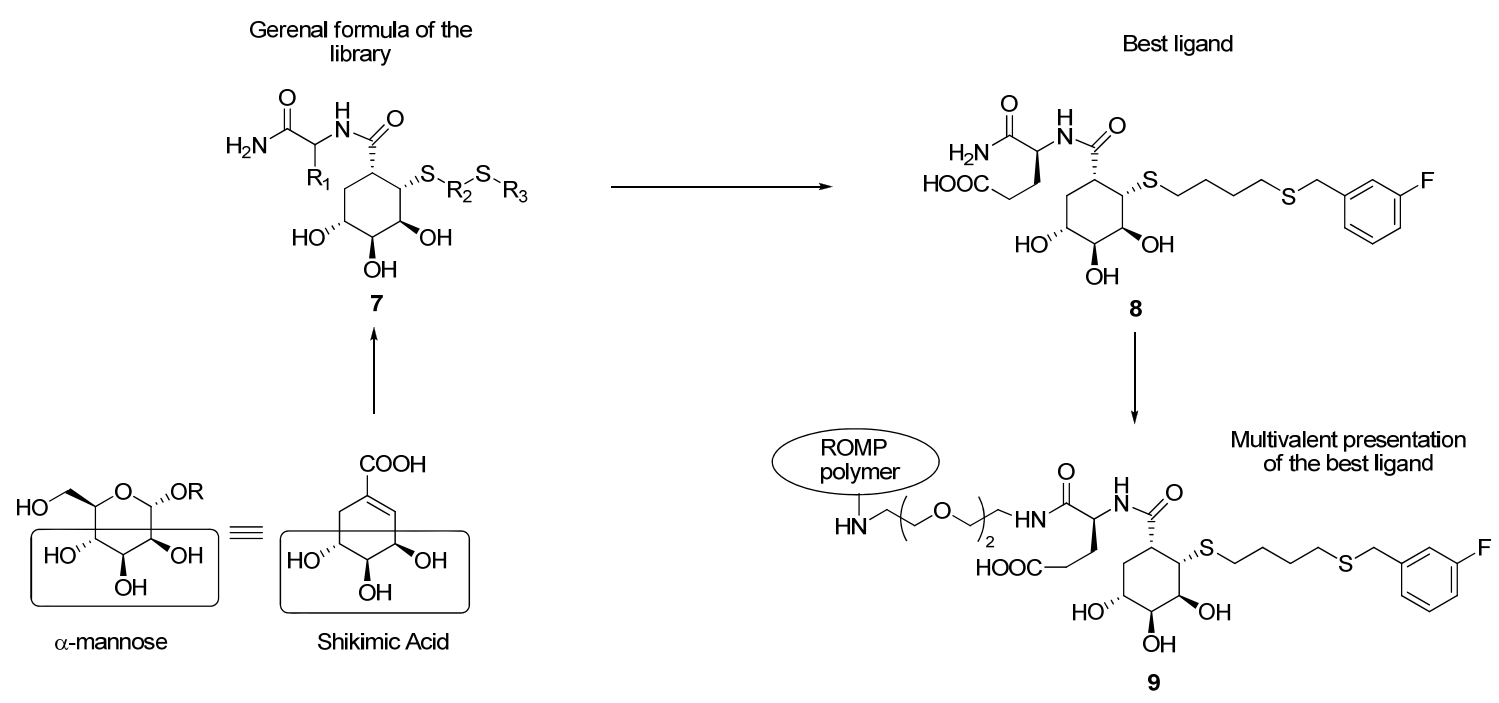

Figure 4. Kiessling shikimic acid-derived glycomimetic strategy to prepare DC-SIGN inhibitors.

The interaction of DC-SIGN with fucosylated oligosaccharides occurs mainly with branched fucosylated structures bearing terminal galactose residues, such as the Lewis antigens. An X-ray structure is available for the DC-SIGN-Lewis-X complex. ${ }^{41 \mathrm{~b}}$ The fucose residue binds in the primary $\mathrm{Ca}^{2+}$ site, and the galactose residue is stabilized by $\mathrm{H}$-bonding in a second binding area of DC-SIGN. Using the 3D structure of Lewis-X as a template, our group designed the first monovalent fucose-based artificial ligand of DC-SIGN 10. ${ }^{54}$ (Figure 5) The ligand was designed using an $\alpha$-fucosylamide anchor, which can drive the molecule to DC-SIGN primary binding site, and connecting it to a galactose mimic via a cyclic cis- $\beta$-aminoacid linker. Amide bonds were chosen to connect the three elements of the molecule, in order to achieve synthetic simplicity as well as chemical and metabolic stability. A second ligand was also prepared by substitution of the complex galactose mimic by a simple acetamide group. (Figure 5) DC-SIGN binding studies performed by SPR (Surface Plasmon Resonance) biosensor showed that compunds 10 and 11a inhibit DC-SIGN better than the natural ligand Lewis-X trisaccharide. The small difference in affinity between 10 and 11a suggested that the galactose mimic fragment in $\mathbf{1 0}$ gave a limited contribution to the binding interaction.

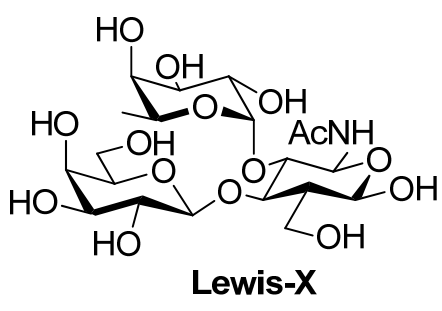

$\left(\mathrm{IC}_{50} 0.8 \mathrm{mM}\right)$

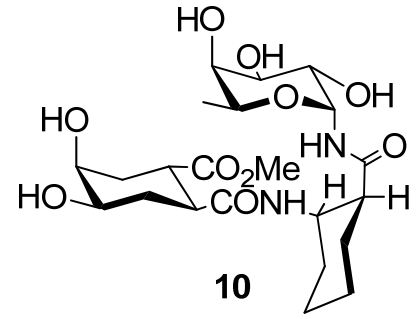

$\left(\mathrm{IC}_{50} 0.35 \mathrm{mM}\right)$

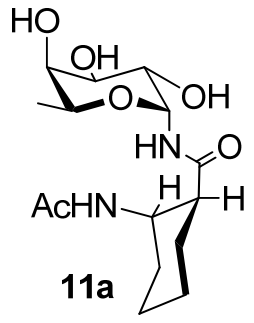

$\left(\mathrm{IC}_{50} 0.5 \mathrm{mM}\right)$

Figure 5. First series of Fucose-based DC-SIGN inhibitors.

This result revealed that fucose residue of $\alpha$-fucosylamides $\mathbf{1 0}$ and 11a interact strongly with DC-SIGN and suggested to replace the galactose mimic in $\mathbf{1 0}$ by other residues to optimize the interaction on the secondary binding site of the lectin. Following this 
strategy, a second generation of fucose-based ligands was synthesized using as lead compound the fucosylamide 11a. A library of 30 compounds with the general formula 11 (Figure 6) was prepared by replacing the acetamide group with residues featuring aromatic groups and/or hydroxyl groups, amino groups or acetamides. ${ }^{55}$ Affinity evaluation of the new ligands $\mathbf{1 1}$ showed that all the molecules synthesized presented the same activity independent of the nature of the $\mathrm{R}$ group.<smiles>[R]C(=O)N[C@H]1CCCC[C@H]1C(=O)N[C@H]1O[C@H](C)[C@@H](O)[C@H](O)[C@H]1O</smiles>

$(1 S, 2 R)$

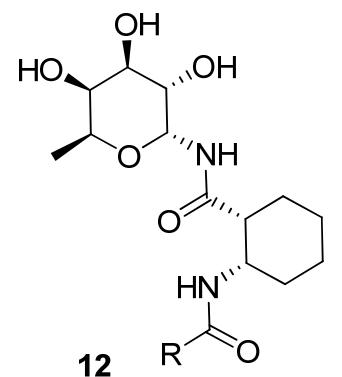

$(1 R, 2 S)$

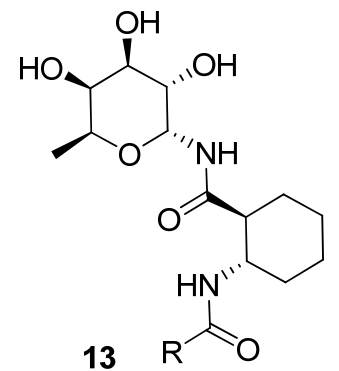

$(1 S, 2 S)$<smiles>[R]C(=O)N[C@H]1CCCC[C@H]1C(=O)N[C@H]1O[C@H](C)[C@@H](O)[C@H](O)[C@H]1O</smiles>

$(1 R, 2 R)$

Figure 6. Second generation of Fucose-based ligands for DC-SIGN.

To examine the effect of the $\beta$-aminoacid linker structure on the activity of the ligands, a new group of molecules was prepared using $\beta$-alanine rather than $(1 S, 2 R)$-2-aminocyclohexanecarboxylic acid as a linker. Interestingly, these simple $\alpha$-fucosyl- $\beta$-alanyl amides showed a similar affinity for DC-SIGN as Lewis-X and all the compounds of the series 11 synthesized. This unexpected results confirmed that the $(1 S, 2 R)$-2-aminocyclohexanecarboxylic acid scaffold selected for the synthesis of $\mathbf{1 1}$ does not enforce optimal interaction of the secondary residue with the protein. To further explore the role of the $\beta$-aminoacid structure in defining ligand-protein interaction, the configuration of the scaffold was changed systematically and a third set of compounds 12-14 was synthesized, where the $\mathrm{R}$ fragment was kept unchanged and the $\beta$-aminoacid configuration was systematically permutated.

The IC50 values of this set confirmed that the activity of most fucosylamides is close to that of Lewis-X. The strongest ligands were the hydroxybenzoic acid derivatives of $\mathbf{1 2}$ $(\mathrm{R}=3-\mathrm{OH}-\mathrm{Ph}$ and $3,5-\mathrm{OH}-\mathrm{Ph})$ with an $\mathrm{IC}_{50}$ of $0.47 \mathrm{mM}$. The main feature of these fucose-based compounds is the selectivity for DC-SIGN. These molecules block the action of DC-SIGN but do not interfere with the action of other lectins, such as Langerin, which play an important in role in the protections mechanism against HIV.

\section{Conclusions}

In conclusion, we have shown that glycomimetic molecules capable of antagonizing the native ligands of various medically relevant lectins are being actively designed and synthesized by various groups. The general approach used in this research takes advantage of the 3D structure of known oligosaccharide ligands and of features of the available X-ray structures of the lectin complexes to design small-molecule monovalent ligands often endowed with limited protein affinity, but with improved drug-like properties relative to sugars. This approach has allowed to identify promising leads which are giving encouraging results also in terms of selectivity. Multivalent 
presentation on polymeric scaffolds of these ligands has allowed to obtain high-affinity antagonists. Much work remains to be done to allow selection of polyvalent scaffolds and ligands optimal in size, shape and valency and finely tuned to the supramolecular architecture of individual lectins.

1. Kamerling, J. P. Comprehensive Glycoscience. From Chemistry to System Biology, Vols. 3 and 4, Elsevier, Amsterdam, 2007.

2. (a) Gabius, H.-J., André, S., Jiménez-Barbero, J., Romero, A., Solıs, D., Trends in Biochemical Sciences, 2011, 36, 298-313; (b) Gabius, H.-J., Siebert, H.-C., André, S., Jiménez-Barbero, J. Rüdiger, H., ChemBioChem, 2004, 5, 740-764.

3. (a) Structural Medicine: The Importance of Glycomics for Health and Disease, European Science Foundation, Strasbourg, 2006; (b) Werz, D. B., Seeberger P. H. in Chemical Biology: From Small Molecules to Systems Biology and Drug Design (Eds.: S. L. Schreiber, T. M. Kapoor, G. Wess) Wiley-VCH, Weinheim, 2007, 668-691; (c) Pilobello, K. T., Mahal, L. K., Curr. Opin. Chem. Biol., 2007, 11, 300-305; (d) Paulson, J. C., Blixt, O., Collins, B. E., Nat. Chem. Biol., 2006, 2, 238-248; (e) Luetteke, T., Bohne-Lang, A., Loss, A., Goetz, T., Frank, M., von der Lieth, C.-W., Glycobiology, 2006, 16, 71R$81 \mathrm{R}$.

4. Bertozzi, C. R., Kiessling, L. L., Science, 2001, 291, 2357-2364.

5. Reviewed in: (a) Culf, A. S., Cuperlovic-Culf, M., Ouellette, R. J., OMICS, 2006, 10, 289-310; (b) Turnbull, J. E., Field, R. A., Nat Chem. Biol., 2007, 3, 74-77.

6. von der Lieth, C.-W., Ardá Freire, A., Blank, D., Campbell, M. P., Ceroni, A., Damerell, D. R., Dell, A., Dwek, R. A., Ernst, B., Fogh, R., Frank, M., Geyer, H., Geyer, R., Harrison, M. J., Henrick, K., Herget, S., Hull, W.E., Ionides, J., Joshi, H. J., Kamerling, J. P., Leeflang, B. R., Lütteke, T., Lundborg, M., Maass, K., Merry, A., Ranzinger, R., Rosen, J., Royle, L., Rudd, P. M., Schloissnig, S., Stenutz, R., Vranken, W. F., Widmalm, G., Haslam, S. M., Glycobiology, 2011, 21, 493-502; (b) see http://www.eurocarbdb.org and links therein.

7. Werz, D. B., Ranzinger, R., Herget, S., Adibekian, A., von der Lieth, C.-W., Seeberger P. H., ACS Chem. Biol., 2007, 2, 685-691.

8. (a) Ernst, B., Magnani, J. L., Nat. Rev. Drugs Discovery, 2009, 8, 661-677; (b) Cheshev, P., Bernardi, A., Chem. Eur. J., 2008, 14, 7434-7441.

9. (a) Winchester, B., Fleet, G. W. J., Glycobiology, 1992, 2, 199210; (b) Pearson, M. S. M., Mathé-Allainmat, M., Fargeas, V., Lebreton, J., Eur. J. Org. Chem., 2005, 2159-2191 and references therein; (c) Nishimura, Y. in Iminosugars: From Synthesis to Therapeutic Applications, ed. P. Compain and O. R. Martin, Wiley-VCH, Weinheim, Germany, 2007, p 269 (d) AguilarMoncayo, M., Garcia-Moreno, M. I., Trapero, A., Egido-Gabas, M., Llebaria, A., Garcia Fernandez, J. M., Ortiz, C., Org. Biomol. Chem., 2011, 9, 36983713 and references therein.

10. von Itzstein,, M., Nat. Rev. Drug Discovery, 2007, 6, 967-974.

11. Gross, B. J., Swoboda, J. G., Walker, S., J. Am. Chem. Soc., 2008, 130, 440441.

12. (a) Ghazarian, H., Idoni, B., Oppenheimer, S. B., Acta Histochemica, 2011, 113, 236-247; (b) Weis W. I., Taylor M. E., Drickamer, K., Immun. Rev., 
1998, 163, 19-34; (c) Gabius, H.J., Andre, S., Kaltner, H., Siebert H. C., Biochem. Biophys. Acta, 2002, 1572, 165-177; (d) Pieters, R. J., ChemBioChem, 2006, 7, 721-728; (f) Sharon, N., Lis, H., Glycobiology, 2004, 14, 53R-62R; (e) Sanchez-Ruderisch, H., Fischer, C., Detjen, K. M., Welzel, M., Wimmel, A., Manning, J. C., Andre, S., Gabius, H.-J., FEBS J., 2010, 277, $3552-3563$.

13. Cipolla, L., Araijo, A. C., Bini, D., Gabrielli, L., Russo, L., Shaikh, N., Expert. Opin. Drug Discov., 2010, 5, 1-17.

14. Cipolla, L., La Ferla, B., Airoldi, C., Zona, C., Orsato, A., Shaikh, N., Russo, L., Nicotra, F., Fut. Med. Chem., 2010, 2, 587-599.

15. (a) Varki, A., Glycobiology, 1993, 3, 97-130; (b) Dwek, R. A., Chem. Rev., 1996, 96, 683-720; (c) Lee, Y. C., Lee, R. T., Acc. Chem. Res., 1995, 28, 321327. (d) Seeberger, P. H., Werz, D. B., Nature, 2007, 446, 1046-1051.

16. Aplander, K., Marttila, M., Manner, S., Arnberg, N., Sterner, O., Ellervik, U., J. Med. Chem., 2011, 54, 8627-8641.

17. Roldos, V., Canada, F. J., Jiménez-Barbero, J., ChemBioChem, 2011, 12, 9901005.

18. Binder, F. P. C., Ernst, B., Chimia 2011, 65, 210-213.

19. (a) Cheshev, P., Morelli, L., Marchesi, M., Podlipnik, C., Bergstrom, M., Bernardi, A., Chemistry Eur. J. 2010, 16, 1951-1967; (b) Tran, H.-A., Kitov, P. I., Paszkiewicz, E., Sadowska, J. M., Bundle, D., Org. Biomol. Chem., 2011, 9, 3658-3671.

20. (a) Klein, T., Abgottspon, D., Wittwer, M., Rabbani, S., Herold, J., Jiang, X.H., Kleeb, S., Luthi, C., Scharenberg, M., Bezencon, J., Gubler, E., Pang, L.J., Smiesko, M., Cutting, B., Schwardt, O., Ernst, B., J. Med. Chem., 2010, 53, 6670-6675; (b) Schwardt, O., Rabbani, S., Hartmann, M., Abgottspon, D., Wittwer, M., Kleeb, S., Zalewski, A., Smiesko, M., Cutting, B., Ernst, B., Bioorg. Med. Chem., 2011, 19, 6454-6473; (c) Hartmann M., Lindhorst T. K., Eur. J. Org. Chem., 2011, 3583-3609 and references therein.

21. (a) Mesch, S., Lemme, K., Wittwer, M., Koliwer-Brandl, H., Schwardt, O., Kelm, S., Ernst, B., ChemMedChem, 2011, DOI:10.1002/cmdc.201100407; (b) Zeng, Y., Rademacher, C., Nycholat, C. M., Futakama, S., Lemme, K., Ernst, B., Bioorg. Med. Chem. Lett., 2011, 21, 5045-5049; (c) Schwardt, O., Koliwer-Brandl, H., Zimmerli, R., Mesch, S., Rossato, G., Spreafico, M., Vedani, A., Kelm, S., Ernst B., Bioorg. Med. Chem., 2010, 18, 7239-7251.

22. Chambre, Y. M., Giguere, D., Blanchard, B., Rodriguez, J., Rocheleau, S., Neault, M., Rauthu, S., Papadopoulos, A., Arnold, A. A., Imberty, A., Roy, R., Chem. Eur. J., 2011, 17, 6545-6562

23. Geijtenbeek, T. B. H., Torensma, R., Van Vliet, S. J., van Duijnhoven, G. C. F., Adema, G. J., van Kooyk, Y., Figdor, C. G., Cell, 2000, 100, 575-585.

24. (a) Yuasa, H., Izumi, M., Hashimoto, H., Curr. Top. Med. Chem., 2009, 9, 7686; (c) Arjona, O., Gómez, A.M., López, J.C., Plumet, J., Chem. Rev., 2007, 107, 1919-2036.

25. Koester, D. C., Holkenbrink, A., Werz, D. B., Synthesis, 2010, 19, 3217-3242 and references cited therein.

26. (a) Lindhorst, T. K., Top. Curr. Chem., 2002, 218, 201-235; (b) Pieters, R. J., Trends in glycoscience and glycotechnology, 2004, 16, 243-244. (c) Lahmann, M., Top. Curr. Chem., 2009, 288, 17-65; (d) Chabre, Y. M., Roy, R., Curr. Top. Med. Chem., 2008, 8, 1237-1285. 
27. (a) Kalia, N., Janz, K., DeBernardo, S., Bedard, P. W., Camphausen, R. T., Tam, S., Tsao, D. H. H., Keith, J. C., Nickerson-Nutter, C., Shilling, A., Young-Sciame, R., Wang, Q., J. Med. Chem., 2007, 50, 21-39; (b) Kalia, N., Janz, K., Huang, A., Moretto, A., DeBernardo, S., Bedard, P. W., Tam, S., Clerin, V., Keith, J. C., Tsao, D. H. H., Sushkova, N., Shaw, G. D., Camphausen, R. T., Schaub, R. G., Wang, Q., J. Med. Chem., 2007, 50, 40-64. (c) Borrok, M. J., Kiessling, L. L., J. Am. Chem. Soc., 2007, 129, 1278012785.

28. Bhunia, A., Schwardt, O., Gathje, H., Gao, G.P., Kelm, S., Benie, A. J., Hricovini, M., Peters, T., Ernst, B., ChemBioChem, 2008, 9, 2941-2945.

29. Roseman, S., J. Biol. Chem., 2001, 276, 41527-41542.

30. Brocca, P., Bernardi, A., Raimondi, L., Sonnino, S., Glycoconjugate J., 2000, 17, 283-299.

31. Yuriev, E., Farrugia, W., Scott, A.M., Ramsland, P.A., Immunol. Cell Biol., 2005, 83, 709-717.

32. Jiménez-Barbero, J., Asensio, J. L., Cañada, F. J., Poveda, A., Curr. Opin. Struct. Biol., 1999, 9, 549-555.

33. Mammen, M., Choi, S.-K., Whitesides, G. M., Angew. Chem. Int. Ed., 1998, 37, 2755-2794.

34. (a) Kitov, P. I., Sadowska, J. M., Mulvey, G., Armstrong, G. D., Ling, H., Pannu, N. S., Read, R. J., Bundle, D. R., Nature, 2000, 403, 669-672; (b) Fan, E. K., Zhang, Z. S., Minke, W. E., Hou, Z., Verlinde, C. L. M. J., Hol, W. G. J., J. Am. Chem. Soc., 2000, 122, 2663-2664; (c) Arosio, D., Fontanella, M., Baldini, L., Mauri, L, Bernardi, A., Casnati, A., Sansone, F., Ungaro, R., J. Am. Chem. Soc., 2005, 127, 3660-3661; (d) Pukin, A. V., Branderhorst, H. M., Sisu, C., Weijers, C. A. G. M., Gilbert, M., Liskamp, R. M. J., Visser, G. M., Zuilhof, H., Pieters, R. J. ChemBioChem, 2007, 8, 1500-1503.

35. (a) Tabarani, G.,Thepaut, M., Stroebel, D., Ebel, C., Vives, P., Vachette, P., Duramd, D., Fieschi, F., J. Biol. Chem., 2009, 284, 21229-21240; (b) SerranoSierra-Gomez, D., Sierra-Filardi, E., Martinez-Nuñez, E. T., Caparros, E., Delgado, R., Muñoz-Fernandez, A., Abad, M. A., Jiménez-Barbero, J., Leal, M., Corbi, A. L., J. Biol. Chem., 2008, 283, 3889-3903. (c) Feinberg, H., Guo, Y., Mitchell, D. A., Drickamer, K., Weis, W. I., J. Biol. Chem., 2005, 280, 1327-1335; (d) Mitchell, D. A., Fadden, A. J., Drickamer, K., J. Biol. Chem., 2001, 276, 28939-28945.

36. (a) Geijtenbeek, T. B. H., Kwon, D. S., Torensma, R., Van Vliet, S. J., van Duijnhoven, G. C. F., Middel, J., Cornelissen, I. L. M. H. A., Nottet, H. S. L. M., Kewal Ramani, V. N., Littman, D. R., Figdor, C. G., van Kooyk, Y., Cell, 2000, 100, 587-597; (b) Lozach, P.-Y, Lortat-Jacob, H., De Lacroix De Lavalette, A., Staropoli, I., Foung, S., Amara, A., Houles, C., Fieschi, F., Schwartz, O., Virelizier, J.-L, Arenzana-Seisdedos, F., Altmeyer, R., J. Biol. Chem., 2003, 278, 20358-20366; (c) Alvarez, C. P., Lasala, F., Carrillo, J., Muniz, O., Corbi, A. L., Delgado, R., J. Virol., 2002, 76, 6841-6844; (d) Han, D. P., Lohani, M., Cho, M. W., J. Virol., 2007, 81, 12029-12039.

37. (a) Tailleux, L., Schwartz, O., Herrmann, J. L., Pivert, E., Jackson, M., Amara, A., Legres, L., Dreher, D., Nicod, L. P., Gluckman, J. C., Lagrange, P. H., Gicquel, B., Neyrolles, O., J. Exp. Med., 2003, 197, 121-127; (b) Kang, Y. S., Kim, J. Y., Bruening, S. A., Pack, M., Charalambous, A., Pritsker, A., Moran, T. M., Loeffler, J. M., Steinman, R. M., Park, C. G., Proc. Natl. Acad. Sci., 2004, 101, 215-220. 
38. (a) Cambi, A., Gijzen, K., de Vries, J. M., Torensma, R., Joosten, B., Adema, G. J., Netea, M. G., Kullberg, B. J., Romani, L., Figdor, C. G., Eur. J. Immunol., 2003, 33, 532-538; (b) Serrano-Gomez, D., Dominguez-Soto, A., Ancochea, J., Jimenez-Heffernan, J. A., Leal, J. A., Corbi, A. L., J. Immunol., 2004, 173, 5635-5643.

39. (a) Colmenares, M., Puig-Kroger, A., Pello, O. M., Corbi, A. L., Rivas, L., J. Biol. Chem., 2002, 277, 36766-36769; (b) van Die, I., van Vliet, S. J., Nyame, A. K., Cummings, R. D., Bank, C. M. C., Appelmelk, B., Geijtenbeek, T. B. H., van Kooyk, Y., Glycobiology, 2003, 13, 471-478.

40. (a) Reina, J. J., Bernardi, A., Clerici, M., Rojo, J., Fut. Med. Chem., 2010, 2, 1141-1159 and references cited therein. (b) Sánchez-Navarro, M., Rojo J., Drugs News \& Perspectives, 2010, 23, 557-572.

41. (a) Feinberg, H., Castelli, R., Drickamer, K., Seeberger, P. H., Weis, W. I., J. Biol. Chem., 2007, 282, 4202-4209. (b) Guo, Y., Feinberg, H., Conroy, E., Mitchell, D. A., Alvarez, R., Blixt, O., Taylor, M. E., Weis, W. I., Drickamer, K., Nat. Struct. Mol. Biol., 2004, 11, 591- 598. (c) Feinberg, H., Mitchell, D. A., Drickamer, K., Weis, W. I., Science, 2001, 294, 2163-2166.

42. Reina, J.J., Sattin, S., Invernizzi, D., Mari, S., Martinez-Prats, L., Tabarani, G., Fieschi, F., Delgado, R., Nieto, P.M., Rojo, J.. Bernardi, A., ChemMedChem, 2007, 2, 1030-1036.

43. Adams, E. W., Ratner, D. M., Bokesch, H. R., McMahon, J. B., O'Keefe, B. R., Seeberger, P. H., Chem. Biol., 2004, 11, 875-881.

44. Mari, S., Posteri, H., Marcou, G., Potenza, D., Micheli, F., Cañada, F. J., Jiménez-Barbero, J., Bernardi, A., Eur. J. Org. Chem., 2004, 5119-5125.

45. Mari, S., Sánchez-Medina, I., Mereghetti, P., Belvisi, L., Jiménez-Barbero, J., Bernardi, A., Carb. Res., 2007, 342, 1859-1868.

46. Sattin, S., Daghetti, A., Thépaut, M., Berzi, A., Sánchez-Navarro, M., Tabarani, G., Rojo, J., Fieschi, F., Clerici, M., Bernardi, A., ACS Chem. Biol., 2010, 5, 301-312;

47. Luczkowiak, J., Sattin, S., Sutkeviciute, I., Reina, J. J., Sánchez-Navarro, M., Thépaut, M., Martínez-Prats, L., Daghetti, A., Fieschi, F., Delgado, R., Bernardi, A., Rojo, J., Bioconjugate Chem., 2011, 22, 1354-1365.

48. Lasala, F., Arce, E., Otero, J. R., Rojo, J., Delgado, R., Antimicrob. Agents Chemother., 2003, 47, 3970-3972.

49. Obermajer, N., Sattin, S., Colombo, C., Bruno, M., Svajger, U., Anderluh, M., Bernardi, A., Mol. Div., 2011, 15, 347-360.

50. Varga, N. et al., manuscript in preparation.

51. Crystal Structure of DC-SIGN carbohydrate recognition domain complexed with $\mathrm{Man}_{4}$ Protein Data Bank. http://www.pdb.org/pdb/explore/explore.do?structureId=1SL4. (Accessed 6 July 2009)

52. (a) Schuster, M. C., Mann, D. A., Buchholz, T. J., Johnson, K. M., Thomas, W. D., Kiessling, L. L., Org. Lett., 2003, 5, 1407-1410. (b) Garber, K. C. A., Wangkanont, K., Carlson, E. E., Kiessling, L. L., Chem. Comm., 2010, 46, 6747-6749.

53. (a)Courtney, A. H., Puffer, E. B., Pontrello, J. K., Yang Z. Q., Kiessling, L. L., Proc. Natl. Acad. Sci. USA, 2009, 106, 2500-2505; (b) Kiessling, L. L., Splain, R. A., Annu. Rev. Biochem., 2010, 79, 619-653; (c) Bielawski, C. W., Grubbs, R. H., Progress in Polymer Science, 2007, 32, 1-29. 
54. Timpano, G., Tabarani, G., Anderluh, M., Invernizzi, D., Vasile, F., Potenza, D., Nieto, P. M., Rojo, J., Fieschi, F., Bernardi, A., ChemBioChem, 2008, 9, 1921-1930.

55. Andreini, M., Doknic, D., Sutkeviciute, I., Reina, J. J., Duan, J. X., Chabrol, E., Thepaut, M., Moroni, E., Doro, F., Belvisi, L., Weiser, J., Rojo, J., Fieschi, F., Bernardi, A., Org. Biomol. Chem., 2011, 9, 5778-5786 (b) Obermajer, N., Svajger, U., Jeras, M., Sattin, S., Bernardi, A., Anderluh, M., Anal. Biochem., 2010, 406, 222-229. 